\title{
Observaciones acerca del uso de las ordalías durante la Antigüedad Tardía (siglos IV-VII d.C.) ${ }^{1}$
}

\section{Remarks on the Use of Ordeals in Late Antiquity $\left(4^{\text {th }} \cdot-7^{\text {th }}\right.$. Centuries A.D.)}

\author{
Esteban MORENO RESANO \\ Departamento de Ciencias de la Antigüedad \\ Área de Historia Antigua \\ Facultad de Filosofía y Letras. Universidad de Zaragoza \\ estmores@unizar.es
}

Recibido: 21 de febrero de 2014

Aceptado: 31 de marzo de 2014

\section{RESUMEN}

Las ordalías se pueden definir como procedimientos judiciales probatorios distintos de los testificales y documentales. Fueron practicadas entre los siglos IV y VII tanto por los romanos como por los germanos que se habían establecido en los territorios del Imperio de Occidente, aunque, en cada caso, su funcionalidad y formas eran distintas. Entre los romanos nunca contaron con valor jurídico, por lo que se desarrollaron al margen del sistema judicial. En consecuencia, sus resultados no eran vinculantes, aunque por convención solían ser admitidos como prueba. Sin embargo, eran usos judiciales ordinarios entre los germanos, si bien se aplicaban cuando no había otros modos de prueba. Para unos y otros, les atribuyeran o no valor religioso, su práctica revelaba ser un modo expeditivo de resolver litigios.

PALABRAS CLAVE: Ordalías, Imperio romano tardío, Reinos germánicos.

\begin{abstract}
Ordeals can be defined as probatory judicial proceedings other than those testimonial and documentary. They were performed between the $4^{\text {th }}$ and $7^{\text {th }}$ centuries by both the Romans and the Germans who had settled in the territories of the Western Empire, although in each case, their functionality and forms were different. Among the Romans the ordeals were never provided with legal value, therefore they were developed outside the judicial system. Consequently, their results were not binding, although by convention they used to be admitted as evidence. However, ordeals were ordinary judicial practice among the Germans, although only applied when no other probatory means were possible. For one and another people, with or without religious value attributed, their practice meant an expeditious way of resolving disputes.
\end{abstract}

KEYWORDS: Ordeals, Late Roman Empire, Germanic Kingdoms.

\footnotetext{
${ }^{1}$ Este trabajo ha sido realizado gracias a la concesión de un Contrato de Investigación dentro del Subprograma "Ramón y Cajal" (Ministerio de Economía y Competitividad), y se inscribe en el Proyecto de Investigación HAR2008-4355/HIST, financiado por el Ministerio de Economía y Competitividad, y del Grupo Hiberus, subvencionado por el Gobierno de Aragón.
} 


\section{RÉSUMÉ}

L'ordalie peut être définie comme une procédure judiciaire de preuve différente à la preuve testimoniale et documentaire. Des ordalies ont été réalisées entre les $\mathrm{IV}^{\mathrm{e}}$ et $\mathrm{VII}{ }^{\mathrm{e}}$ siècles aussi bien par les Romains que par les peuples germaniques qui s'étaient installés dans les territoires de l'Empire d'Occident, bien que dans chaque cas, leur fonctionnalité et leur formes sont différentes. Parmi les Romains les ordalies n'ont jamais été fournies de valeur légale, raison pour laquelle elles ont été practiquées en dehors du système judiciaire. En conséquence, leurs résultats n'étaient pas contraignants, bien que par convention elles ont pu être admises comme preuve. Cependant, parmi les germaniques elles étaient habituellement utilisées dans la pratique judiciaire ordinaire, bien qu'appliquées seulement lorsque aucune autre mode de preuve n'était pas possible. Aussi bien pour les romains comme pour les germaniques, les ordalies avaient une signification religieuse, et leur pratique révélait être un moyen rapide de régler les différends.

MOTS CLÉ : Preuve, la fin de l'Empire romain, royaumes germaniques.

SUMARIO: 1. El concepto de «ordalía». 2. Marco del estudio. 3. Las ordalías entre los romanos. 3.1. El agua caliente. 3.2. La declaración ante reliquias. 3.3. Las brasas. 4. Las ordalías entre los germanos. 4.1. El duelo. 4.2. El caldero. 5. Conclusiones.

Desde el siglo XIX y hasta los años ochenta del siglo XX, las ordalías han sido estudiadas como un fenómeno característico de la Edad Media. En aras de esta idea, los procedimientos probatorios no testificales ni documentales anteriores al siglo VIII fueron analizados como precedentes del llamado «juicio de Dios» ${ }^{2}$. Sin embargo, los trabajos realizados a partir de mediados de los años noventa han ofrecido una perspectiva completamente diferente de estas prácticas: el uso de las ordalías en contextos judiciales y extrajudiciales no se limitaba a los siglos medievales en Europa occidental, ya que está constatado en culturas tradicionales de todos los continentes ${ }^{3}$. Al igual

${ }^{2}$ J. Villa-Amil y Castro, "Del uso de las pruebas judiciales llamadas vulgares", Boletín Histórico, 10, 1880, pp. 145-155; F. Patetta, Le ordalie, Torino, 1890; C. Von Schwerin, Rituale der Gottesurteile, Heidelberg, 1933; H. Nottarp, Gottesurteilen, München, 1956; P. Fournier, "Quelques observations sur 1'histoire des ordalies au Moyen Âge", Mélanges Gustave Glotz, I, Paris, 1932, pp. 367-376; J. Gaudemet, "Les ordalies au Moyen Âge: doctrine, législation et pratique canoniques", J. Gilissen (ed.), La preuve. Deuxième partie. Moyen Âge et temps modernes, Bruxelles, 1965, pp. 99-135; R. Bartlett, Trial by Fire and Water. The Medieval Judicial Ordeal, Oxford, 1986, pp. 4-12; D. Barthèlemy, "Diversité des ordalies médiévales", Revue Historique, 280, 1988, pp. 3-25; M. Lupoi, Alle radici del mondo giuridico europeo. Saggio storico-comparativo, Roma, 1994, pp. 60, 434, 437, 439, 443, 455; R. Jacob, "Le jugement de Dieu et la transformation de la fonction de juger dans 1'histoire européenne", Histoire de la justice, 4, 1991, pp. 53-78 (=Archives de Philosophie du Droit, 39, 1995, pp. 87-104).

${ }^{3}$ J. Alvarado Planas, El problema del germanismo en el Derecho español. Siglos V-XI, Madrid, 1997, pp. 105-210; S. Kerneis, "Le chaudron des parjures. Rome, les barbares et l'ordalie”, Br. Lemesle (ed.), La preuve en justice de l'Antiquité à nous jours, Rennes, 2003, pp. 23-47; L. Waelkens, "Traces romano-germaniques dans les preuves "germániques", Tijdschrift voor Rechtsgeschiedenis, 75, 2007, pp. 321-331; S. Kerneis, "La verité du droit. Justice oraculaire et gouvernement impérial dans la Gaule romaine", Revue Internationale des Droits de l'Antiquité, 54, 2007, pp. 327-347; S. Kerneis, "Marcher au chaudron. Genèse de l'ordalie dans l'Empire romain (II'-IV ${ }^{\mathrm{e}}$ siècles)", R. Verdier (ed.), Puissances de la nature-justices de l'invisible: du maléfice à l'ordalie, de la magie à sa sanction. Colloque pluridisciplinaire. Universitè Paris-Ouest, 2 décembre 2010, Paris, 2012, pp. 255-268. 
que las ordalías medievales «clásicas», las ordalías de la Antigüedad tardía acusan singularidades acordes con la sociedad y el tiempo en el que se llevaron a la práctica ${ }^{4}$. Estos rasgos definitorios son su origen consuetudinario, su carencia de universal reconocimiento, su carácter fundamentalmente subsidiario, y la restricción de su ámbito de aplicación en función de los vínculos étnicos e institucionales de las partes que entraban en litigio.

\section{El concepto de «ordalía»}

Glotz planteó la existencia de dos tipos de ordalías en sus distintas modalidades: la «primitiva», practicada en virtud del consenso social basado en la tradición, y la «clásica»o «medieval», estrictamente regulada por las normas civiles y canónicas ${ }^{5}$. De este modo, se extendió a prácticas que no eran designadas con un término que, en principio, daba nombre a prácticas medievales. Conforme a esta teoría, el elemento religioso, cristiano o no, era determinante en estos usos.

Recientemente se ha planteado la necesidad de buscar un término más genérico para mencionar el conjunto de estos usos ${ }^{6}$. Pero «ordalía», que procede de la voz germánica ordael («sentencia»), es un sustantivo operativo ${ }^{7}$. Convendría, en todo caso, plantear un nuevo concepto de las mismas. A partir de la teoría «clásica», los sucesivos estudios han coincidido en definir las ordalías como procedimientos probatorios que prescindían de métodos de verificación testifical o documental, que requerían la intervención de fuerzas sobrenaturales mediante su invocación ${ }^{8}$. Sin embargo, algunas ordalías, en concreto, los duelos singulares, no parecen haber exigido necesariamente la concurrencia divina, al menos, hasta el siglo VI. Tampoco parece que hubiera invocación divina ni en los lances sobre los que informa Casiodoro ni en el duelo que dispuso el rey Gontrán para determinar quién era el responsable de haber cazado un búfalo en el bosque real de los Vosgos9. Excepcionalmente, una ley burgundia del año 502 menciona la intervención activa de Dios en el desenlace de un duelo judicial (Deo iudicante) $^{10}$. Sin embargo, a partir del siglo VII, este tipo de duelo es denominado expresamente Dei iudicium ${ }^{11}$. Así pues, se abre la posibilidad de definir la or-

\footnotetext{
${ }^{4}$ P. Brown, "Society and the Supernatural: A Medieval Change", Daedalus, 104, 1975, pp. 133-151.

${ }^{5}$ G. Glotz, L'ordalie dans la Grèce primitive, Paris, 1904, pp. 126-131.

${ }^{6}$ A. A. Nagy, "L'ordalie de la philologie classique ou la tentantion de l'autre", F. Prescendi y Y. Volokhine (eds.), Dans le laboratoire de l'historien des religions. Mélanges offerts à Philippe Borgeaud, Genève, 2011, pp. 134-157, esp. p. 157.

${ }^{7}$ Ordael puede presentar otras variantes. Es el resultado de la unión de las raíces dael, dele o dela (que significan "decidir") con los intensificadores or, ar o ur. Cf. A. A. Nagy, "L'ordalie ...", p. 134.

${ }^{8}$ J. Gaudemet, "Les ordalies ...", pp. 99-102; J. Alvarado Planas, El problema ..., pp. 105-110.

${ }^{9}$ Cass., Var., III, 23-24; IX, 14; Greg. Turon. Hist. Franc., X, 10.

${ }^{10}$ Lex Burg., XLV.

${ }^{11}$ Lex Burg., 45; Edic. Roth. 198; Fred. Chron., IV, 51; Edict. Roth., 198 (siglo VII). Las menciones al Dei iudicium que aparecen en los Decreta Tassilonis (Lex Baiu. Decr. Tass., IV, 6; Lex Baiu. 16,12; 17,5),
} 
dalía, de modo genérico, como un procedimiento observado con el fin de dirimir un litigio al margen de los medios probatorios habituales, que podía aportar pruebas concluyentes si no las había testimoniales o documentales, o, simplemente, zanjar una discusión que, de otro modo, se antojaba irresoluble ${ }^{12}$. No obstante, en las sociedades tradicionales, como eran las antiguas, estos usos estaban impregnados de religiosidad, de modo que, al margen de la mecánica de su desarrollo, existía la convicción, más o menos consensuada, de que la providencia divina tutelaba su transcurso con vistas a un desenlace justo.

\section{Marco del estudio}

Dentro del amplio conjunto de usos que pueden ser considerados «ordalías», el presente trabajo sólo se propone estudiar unos casos determinados, a saber, los registrados entre los siglos IV y VII d.C. en los territorios que pertenecieron al Imperio romano y que después quedaron divididos en distintos reinos germánicos. Las primeras referencias a ordalías en época romana tardía aparecen en el llamado Panegírico Latino del año $310^{13}$. De este testimonio partirá el estudio. Acabará en el siglo VIII, cuando las ordalías comenzaron a tener una consideración jurídica distinta. Hasta esa centuria, se cuestionó en numerosas ocasiones la eficacia de las ordalías para dirimir causas, siendo ésta su razón de ser. El rey Teodorico, por medio de la mano de Casiodoro, admitió que se celebraran duelos judiciales entre los ostrogodos, pues se trataba de una tradición, a pesar de calificarla de consuetudo peruersa, instando a sus súbditos a dirimir las causas en procesos convencionales, de modo racional y civilizado ${ }^{14}$. Gregorio de Tours recuerda que, en ocasiones, el resultado de la prueba trataba de ser impugnado como una obra de magia ${ }^{15}$. Tampoco el rey Gontrán se mostró satisfecho del resultado del duelo entre el nieto de uno de sus cubicularios y el guarda del bosque de los Vosgos, saldado con la muerte de ambos combatientes ${ }^{16}$. Si hasta entonces su valor no había sido reconocido de modo unánime, la ley de Liutprando del año 731 les conferirá pleno valor jurídico, en atención a su carácter consuetudinario, no sin expresar sus reservas ${ }^{17}$. Éstas tenían su fundamento en que el

aunque se les atribuye un origen anterior, corresponden, en realidad, a una redacción del siglo VIII. Cf. J. Alvarado Planas, El problema ..., pp. 141, 144; Th. Holzner, Die Decreta Tassilonis: Regelegungsgehalt, Verhältnis zur Lex Baiuvariorum und politische Implikationen, Berlin, 2010.

${ }^{12}$ L. Waelkens, "Traces ...”, p. 327.

${ }^{13}$ Pan. Lat. VII, 21.

${ }^{14}$ Cass., Var., III, 23 (consuetudinem peruersam); III, 24 (rationabiliter ... sub ciuilitate).

${ }^{15}$ Greg. Turon., Hist. Franc., II, 1; Liber mirac., LXXXI.

${ }^{16}$ Greg. Turon., Hist. Franc., X, 10.

${ }^{17}$ L. Liutp., 118 (65): (...) Quia incerti sumus de iudicio Dei, et multos audiuimus per pugnam sine iustitia causam suam perdere. Sed propter consuetudinem gentis nostrae Langobardorum legem impiam uetare non possummus. Cf. J. Gaudemet, "Les ordalies ...", p. 105; J. Alvarado Planas, El problema ..., pp. 140-141, 145. 
resultado de muchos duelos había dado en dirimir causas sine iustitia. Sin embargo, un siglo después, en 809, Carlomagno sancionó la plena validez del «juicio de Dios» al margen de las dudas que pudieran surgir al respecto ${ }^{18}$.

Las ordalías de los romanos y de los germanos eran diferentes en sus formas y funcionalidad. Entre los ciudadanos romanos, nunca tuvieron valor procesal alguno, aunque sí repercusiones desde el punto de vista social; entre los germanos, por el contrario, su práctica era un uso aceptado por el peso de la costumbre y tenía pleno valor decisorio, aunque, a veces se cuestionara. Además, aunque la historiografía haya tendido a identificar las ordalías con el llamado «juicio de Dios», sólo los francos merovingios y los lombardos asimilaban una y otra cosa. Se puede deducir, por consiguiente, que el empleo de un tipo u otro de ordalía, así como su valor, dependía del origen étnico de las personas que ejercían de partes.

\section{Las ordalías entre los romanos}

Aunque la información no es abundante ni siempre fiable, se tiene noticia del uso de tres tipos de ordalías entre los romanos en los últimos siglos de la Antigüedad: el agua caliente, la testificación ante reliquias y la manipulación del fuego. Se pueden considerar prácticas acogidas dentro de la tradición romana, con independencia de que fueran originarias de algunas culturas provinciales. El agua caliente es la primera forma documentada, a comienzos del siglo IV. Más tarde aparece la declaración procesal ante reliquias, y, por último, el empleo probatorio de ascuas o fuego. Con excepción de la última modalidad, las ordalías aceptadas por la tradición romana, politeístas o cristianas, genuinas o adoptadas de pueblos conquistados, partían de la consideración de que determinados lugares eran sede de específicas facultades sobrenaturales, que propiciaban la realización de ciertos ritos. Es preciso advertir que las ordalías no fueron practicadas por los romanos en el curso de procesos judiciales, sino fuera de ellos. En todo caso, sólo se ha comprobado su aplicación en la instrucción de causas eclesiásticas, y de modo muy excepcional.

\subsection{El agua caliente}

Las más antiguas formas de ordalías que se conoce entre los romanos requerían el uso ritual de agua caliente. La noticia procede el llamado Panegírico latino del año 310 , dedicado al emperador Constantino ${ }^{19}$. En el discurso se da cuenta de un ritual ordálico que se celebraba en el santuario dedicado a Apolo Granuo ${ }^{20}$. Constan-

\footnotetext{
${ }^{18}$ Capit. I: Vt omnes iuditium Dei credant absque dubitatione. Cf. R. Bartlett, Trial ..., pp. 9-12; J. Alvarado Planas, El problema ..., p. 120; R. Jacob, "Le jugement ..., p. 95.

${ }^{19}$ Sobre el panegírico en cuestión, cf. C. E. V. Nixon y B. S. Rodgers, In Praise of Latin Roman Emperors. The Panegyrici Latini. Introduction, Translation and Historical Commentary with Latin Text of $R$. A. B. Mynors, Berkeley, 1994, pp. 210-217.

${ }^{20}$ El dios tutelar de Grand, Apollo Granuus, estaba completamente romanizado, conforme a la tradición
} 
tino, después de haber vencido a su suegro Maximiano en Massilia, tuvo que desplazarse rápidamente hacia el limes renano para hacer frente a una incursión de los fran$\cos$. Las operaciones militares fueron exitosas, y el emperador se dirigió al conjunto templario de Grand para satisfacer los votos prometidos ${ }^{21}$. El centro cultual tenía fama de ofrecer curaciones milagrosas y favorecer las visiones hipnóticas, pero también se le atribuía la virtud de desenmascarar a los perjuros ${ }^{22}$. El todavía Augusto ilegítimo, que necesitaba demostrar que contaba con el refrendo divino después de que los acuerdos de Carnuntum fueran sistemáticamente incumplidos, no dudó en afirmar que había merecido la visión del dios tutelar del santuario, prometiéndole treinta años de sucesivas victorias militares ${ }^{23}$.

Sin embargo, el anónimo autor del panegírico ruega al emperador en otro pasaje que realice una nueva visita al lugar ${ }^{24}$. En él informa de que el templo de Grand era visitado, entre otras razones, para averiguar si alguien había cometido perjurio. Quien era acusado de haber trasgredido un juramento, podía acudir al templo para someterse a una especie de ordalía y tratar de probar su inocencia. Ésta consistía en beber las aguas termales del lugar, calentadas, no por obra de la naturaleza, sino por beneplácito de la divinidad del lugar, que era Apolo, el dios de la verdad. La ingestión de las aguas calientes era saludable para las personas honestas, pero, se supone que debían de indisponer a los perjuros. Estos ritos no tenían lugar dentro de un proceso judicial. Eran una garantía ante la sociedad para quienes fueran sospechosos de haber jurado en falso o contravenido un juramento de que no lo habían hecho. No consta que Constantino hubiera participado en el rito en alguna ocasión.

Existe otro caso de manipulación ritual del agua caliente entre romanos con fines ordálicos. La noticia aparece en la Historia Francorum de Gregorio de Tours. Un presbítero arriano y un diácono católico disputaban acerca de los dogmas trinitarios. Puesto que ninguno de ambos conseguía convencer a su adversario, resolvieron recurrir a la ordalía del caldero, consistente en llenar de agua un recipiente de bronce y calentarla hasta hervir. Entonces se introducía en el interior un anillo y los repre-

augustea. Por eso Constantino lo escogió para identificarse físicamente con él, cf. B. Saylor Rodgers, "Constantine's Pagan Vision", Byzantion, 50, 1980, pp. 259-278; M ${ }^{a}$ V. Escribano Paño, "La primera visión de Constantino (310)", R. Teja Casuso (ed.), Sueños, ensueños y visiones en la Antigüedad pagana y cristiana, Gijón, 2002, pp. 85-94.

${ }^{21}$ Pan. Lat. VI, XXI, 1-6.

${ }^{22}$ En Grand se practicaba la incubatio, además de las curaciones termales, como demuestra la inscripción AE 1937, No 55. Cf. Y. Burnand, "Informations archéologiques", Gallia, 40, 1982, pp. 342-343. En general, sobre el debate acerca del conjunto templario y sus atribuciones, cf. S. Kerneis, "Le chaudron ...", pp. 28-37; B. Rossignol, "Le droit et la verité. À propos d'une décision inexistante de Trajan et d'une procédure oraculaire inventée en Gaule (réponse à S. Kerneis)", Revue Internationale des Droits de l'Antiquité, 56, 2009, pp. 115-129; S. Kerneis, "En réponse à Benoît Rossignol: l'historiographie dominante et le droit de penser autrement", Revue Internationale des Droits de l'Antiquité, 58, 2011, pp. 181-191.

${ }^{23}$ Pan. Lat. VI, XXI, 1-6.

${ }^{24}$ Pan. Lat. VI, XXI, 7; XXII, 1-2. 
sentantes de cada parte debían introducir el brazo hasta recoger la pieza metálica del fondo del caldero. La razón correspondía a quien extrajera el anillo sin quemarse. El sacerdote pidió al diácono que fuera él el primero. Lo hizo, y, como era de esperar de un relato edificante, su brazo no sufrió daños. Pero el arriano trató de invalidar el rito declarando que era una obra de magia. Finalmente, otro diácono católico tomó el anillo sin sufrir daño alguno. Pero cuando trató de hacer lo mismo el sacerdote hereje, sufrió graves daños. Así quedó demostrada su culpabilidad ${ }^{25}$. El testimonio, sin embargo, ofrece serias dudas acerca de su historicidad: Gregorio no da ni los nombres de los participantes en la ordalía, ni el lugar donde se produjo. De todos modos, la recopilación de este relato hagiográfico refleja que se practicaba el uso ordálico en cuestión, pues aparece descrito con gran detalle, de modo excepcional, en contextos de disputas doctrinales.

\subsection{La declaración ante reliquias}

A lo largo del siglo IV, la progresiva cristianización del Imperio trasladó la realización de este tipo de ceremonias de los templos consagrados a los cultos tradicionales a los lugares donde se veneraban reliquias. Observantes de la antigua religión pública romana o del cristianismo, los hombres de aquella época pertenecían a una misma sociedad, tenían idénticos problemas e inquietudes y buscaban soluciones parecidas $^{26}$. Agustín de Hipona hace referencia a dos casos concretos. Según el obispo, se presentó un ladrón ante la sepultura de los mártires Gervasio y Protasio en Milán, con la intención de prestar juramento en falso. Sin embargo, como dichas reliquias tenían la virtud de hacer confesar a los demonios, el perjuro confesó su culpa y devolvió lo sustraído ${ }^{27}$.

Vista la eficacia del procedimiento de comparecer ante la sepultura de un santo para obtener confesión, Agustín envió en 404 a dos clérigos de su diócesis a testificar ante el sepulcro del mártir Félix de Nola. El caso era extraordinariamente complicado: Bonifacio, un presbítero de la diócesis de Hipona, había sido denunciado por un diácono que esperaba las órdenes sacerdotales por haberle hecho «una proposición impúdica». No había pruebas por ninguna de las partes, así que les planteó la posibilidad de testificar ante las reliquias de San Félix, con la esperanza de que el culpable confesara serlo. Aunque suponía un desplazamiento desde África a Italia, los litigantes aceptaron la solución. Agustín eligió este procedimiento probatorio, porque había re-

\footnotetext{
${ }^{25}$ Greg. Turon., Liber mirac., LXXXI. Cf. J. Alvarado Planas, El problema .., p. 151, n. 192.

${ }^{26}$ P. Veyne, Quand notre monde est devenu chrétien (312-394), Paris, 2007 (cito la traducción castellana: El sueño de Constantino. El fin del Imperio pagano y el nacimiento del mundo cristiano, Barcelona, 2008, pp. 140-141).

${ }^{27}$ Aug. Hipp., Ep. LXXVIII, 3: Nam et nos nouimus Mediolani apud memoriam sanctorum, ubi mirabiliter et terribiliter daemones confitentur, furem quemquam, qui ad eum locum uenerat ut falsum iurando deciperet, compulsum fuisse confiteri furtum, et quod abstulerat reddere (...).
} 
sultado inútil la búsqueda de testimonios ${ }^{28}$. Acudieron a Nola, pero ninguno de los dos testificó. El obispo, finalmente, dio la razón al presbítero, en consideración de su buena fama, aunque la sentencia definitiva quedaba en manos de un tribunal eclesiástico $^{29}$. Se desconoce cómo concluyó la causa.

La ordalía celebrada en Milán no se realizó como parte de la instrucción de un proceso judicial, sino de una prueba de carácter privado de la que dependía la consideración social del supuesto malhechor. También es interesante observar que cuando Agustín de Hipona propuso a los dos encausados acudir al sepulcro del mártir Félix en Nola, lo hizo dentro de una instrucción eclesiástica preliminar, y no propiamente en el iudicium episcopale, que correspondía a un tribunal de seis obispos ${ }^{30}$. Agustín tenía que adoptar una decisión: mantener o no en sus funciones al sacerdote Bonifacio. Además, la comparecencia ante las reliquias del mártir Félix se hizo de mutuo acuerdo entre las partes. Esto supone que tampoco era una prueba aceptada de modo general entonces ni siquiera en los procesos eclesiásticos y que su resultado tampoco hubiera sido vinculante si no se hubiera habido consenso en aceptarla.

Tampoco en el siglo VI, cuando escribía Gregorio de Tours, la declaración jurada ante la sepultura de un santo era un procedimiento plenamente aceptado en las causas eclesiásticas. El sucesor de San Martín en ocupar la sede episcopal de Tours, Bricio, fue acusado en 430 de haber mantenido relaciones con una mujer y de haber tenido un hijo. Y no encontró mejor modo de defenderse de los cargos que hacer llamar al supuesto bastardo ante el sepulcro de San Martín. Allí, según señala el relato, cuando fue presentado el niño, que tenía treinta días, le dijo el obispo: Te conmino por Jesucristo, Hijo de Dios omnipotente, a que digas en presencia de todos si yo te engendré. $Y$ él dijo: Tú no eres mi padre. Y como, a ruegos del pueblo, le preguntó quién era su padre, respondió el obispo: no es hijo mío. Pero sus adversarios, presentes en la prueba, rechazaron la ordalía, acusando a Bricio de magia, por lo cual hubo de someterse a una nueva ordalía, consistente en llevar ascuas ardiendo debajo de un bi$\operatorname{rrete}^{31}$. Si se atiende al relato de Gregorio, el episodio no corresponde a un proceso

\footnotetext{
${ }^{28}$ Aug. Hipp., Ep. LXXVIII, 3: Elegi aliquid medium, ut certo placito se ambo constringerent ad locum sanctum se perrecturos, ubi terribiliora opera Dei non sanam cuiuscumque conscientiam multo facilius aperirent, et ad confessionem uel poena uel timore compellerent. (...) Multis enim notissima est sanctitas loci, ubi beati Felicis Nolensis corpus conditum est, quo uolui ut pergerent; quia inde nobis facilius fideliusque scribi potest quidquid in eorum aliquo diuinitus fuerit propalatum. Alvarado propuso que ambos litigantes debían prestar juramento, pero el texto no permite deducirlo. Cf. J. Alvarado Planas, El problema ..., pp. 116-117.

${ }^{29}$ Aug. Hipp., Ep. LXXVIII, 4.

${ }^{30}$ En aquella época, los cánones de los concilios africanos establecían que un presbítero debía ser juzgado por un tribunal de seis obispos, como señalan los Concilios de Cartago de los años 348 y 390 (Conc. Carth. I, c. IX; Conc. Carth. III, cc. VIII y X). Cf. F. J. Cuena Boy, La episcopalis audientia. La justicia episcopal en las causas civiles entre laicos, Valladolid, 1985, p. 63, n. 14.

${ }^{31}$ Greg. Turon., Hist. Franc., II, 1: Tricesimo tertio uero ordinationis suae anno oritur contra eum lamentabilis causa pro crimine. Nam mulier, ad quam cubicularii eius uestimenta deferebant ad abluendum, quae sub specie religionis erat neste mutata, concepit et peperit. Qua de re surrexit omnis populus
} 
eclesiástico, sino a las presiones del pueblo de Tours, enemistados con el obispo, a quien deseaban privar de su cargo.

No es éste el único caso referido por Gregorio de Tours. En otro capítulo de la Historia Francorum, referido a un momento posterior, recuerda que los perjuros confesaban sus culpas o sufrían castigos por jurar en falso. El pasaje en cuestión relata cómo un sujeto que había intervenido en robos y otros crímenes, para exculparse, trató de declarar su inocencia jurando ante la tumba de San Martín de Tous. Pero acabó confesando su culpa. Del mismo modo, un incendiario juró sobre la tumba del santo que no había prendido fuego a la casa de uno de sus vecinos, pero inmediatamente le rodeó una especie de fuego que le atormentaba ${ }^{32}$.

Aunque la falta de nombres y referencias cronológicas por parte del autor permite presumir la dudosa historicidad de los hechos narrados, también es cierto que la comparación de los usos ordálicos que se llevaban a cabo ante el sepulcro de San Martín habían evolucionado con el tiempo: de la simple declaración se había pasado a practicar el juramento. No obstante, ninguna de las dos formas se llevaba a cabo en el curso de procesos. Quienes aceptaban prestar juramento ante reliquias, lo hacían después de haber llegado a un acuerdo con la persona perjudicada por sus acciones. Procede observar, sin embargo, que el vecino incendiario contaba con testimonios en contra (assertio). Esto significa que, en ocasiones, los romanos de la Galia merovingia preferían recurrir a una ordalía antes que a la justicia ordinaria. Ésta debía de ser costosa, poco fiable en sus resoluciones (la venalidad debía de estar muy extendida) y lenta. La justicia consuetudinaria, fundamentada en el consenso, era, por el contrario, rápida y se la tenía por más eficaz. Se atribuía a las ordalías la ventaja de demostrar en el momento de su ejecución si el sospechoso era culpable o no. Si intervenía en

Toronum in ira, et totum crimen super episcopum referunt, uolentes eum unanimiter lapidare. Aiebant enim: Diu pietas sancti tuam celauit luxoriam, nec nos Deus diutius sinit manus tuas indignas osculando pollui. Illo quoque e contrario uiriliter haec negante: Adferte, inquit, infantem ad me. Cumque oblatus fuisset infans, triginta dies ab ortu habens, ait ad eum episcopus: Adiuro te per Iesum Christum, Filium Dei omnipotentis, ut, si ego te generaui, coram cunctis edicas. Et ille: Non es, inquit, tu pater meus. Populis autem rogantibus, ut quis esset pater interrogaret, ait sacerdos: Non est hoc meum. Cf. J. Alvarado Planas, El problema ..., pp. 117-118.

${ }^{32}$ Greg. Turon., Hist. Franc., VIII, 16: (...) Alius uero, qui plerumque in furtis diuersisque sceleribus conmixtus, periurare consueuerat, cum aliquando a quibusdam pro furtu argueritur, ait: Ibo ad basilicam beati Martini, et sacramentis me exuens, innocens reddar. Quo ingrediente, elapsa secure de manu eius, ad usteum ruit, graui cordis dolore perculsus. Confessusque est miser uerbis propriis quae nenerat excusare periuriis. Alius simili modo cum de incendiis domus uicini sui argueritur, ait: Vadam ad templum sancti Martini et, fide data, insons redditurus ero ab hoc crimine. Manifestum erat enim, hunc domum illam incendio concremasse. Abiens autem ad sacramenta danda, conuersus ad eum dixit: Quantum uicinorum tuorum dictat assertio, non eris innocens ab hoc scelere; sed tamen Deus ubique est, et uirtus eius ipsa est forinsecus, quae habetur intrinsecus. Tamen si ita te uana fiducia coepit, quod Deus uel sancti eius in periuribus non ulciscantur, ecce! (...) At ille, eleuatis manibus, ait: Per omnipotentem Deum et uirtutem beati Martini antestitis eius, quia hoc incendium non admisi. Data itaque sacramenta, dum recederent, uisum est ei quasi ab igne circumdare. Et statim ruens in terra, clamare coepit, se a beato antestite uehementer exuri. 
ellas la voluntad divina, ésta actuaba de inmediato. Esta idea no era infundada desde la perspectiva doctrinal cristiana. El libro de los Hechos de los Apóstoles narra cómo los esposos Ananía y Safira murieron súbitamente cuando los demás fieles descubrieron que habían ocultado algunos de sus bienes para no entregarlos al fondo común de la primitiva comunidad cristiana de Jerusalén ${ }^{33}$.

\subsection{Las brasas}

Además del empleo del agua con fines ordálicos y de prestar declaraciones ante reliquias, los ciudadanos romanos que vivían bajo la autoridad de los reyes germanos adquirieron la costumbre de dirimir diferencias mediante el sometimiento a pruebas que conllevaban la manipulación del fuego. La primera noticia que se tiene de este uso data del año 430, y la protagonizó el obispo Bricio de Tours ${ }^{34}$. Bricio, después de que no fuera aceptada la declaración milagrosa de su supuesto hijo ante el sepulcro de San Martín de que no lo era, aceptó someterse a una nueva ordalía, que consistía en llevar ascuas bajo la sobrepelliz, apretándolas contra su pecho, se supone que desde la entrada del templo hasta el lugar donde se encontraban las reliquias. Sus vestimentas resultaron indemnes, lo que no impidió que sus adversarios le empujaran fuera del templo y le expulsaran de la ciudad ${ }^{35}$.

Al igual que la declaración testifical, tampoco fue aceptado por sus adversarios el resultado de esta prueba, por lo que el obispo fue expulsado de su sede. En cualquier caso, este procedimiento no se llevó a cabo en el curso de ningún proceso judicial eclesiástico. De hecho, todo tiene lugar en el contexto de una revuelta popular contra Bricio. Al igual que en las ordalías de tradición romana que antes se han analizado, el acusado se había sometido voluntariamente a la prueba. De todos modos, Gregorio parece referir en un mismo momento cronológico lo que pudo ocurrir en distintas fechas, quizá próximas en el tiempo. El pasaje tiene elementos narrativos propios de la hagiografía, y algunas imprecisiones en el relato inducen a la duda de que la información sea exacta: no hay datos cronológicos precisos y no se menciona por su nombre a ninguno de los actores. La presión sobre el obispo se atribuye a una anónima masa popular revuelta, pero, a buen seguro, los opositores a Bricio eran los notables de la ciudad y sus nombres eran de los más conocidos en Tours.

\footnotetext{
${ }^{33}$ Act. 5, 1-11.

${ }^{34}$ Sobre Bricio de Tours, cf. Ek. Sauser, "Brictius von Tours", Biographisch-Bibliographisch Kirchenlexikon, XIV, 1998, cols. 831-833.

${ }^{35}$ Greg. Turon., Hist. Franc., II, 1: (...) Ille autem ad satisfaciendo adhuc populo prunas ardentes in byrrum suum posuit, et ad se stringens, usque ad sepulchrum beati Martini una cum populorum turbis accedit, proiectasque ante sepulchrum prunas, uestimentum inustum apparuit. Illo quoque sic prosequente: Sicut istud uestimentum ab his ignibus uidetis inlesum, ita et corpus meum a tactu muliebris coiti est inpollutum. Illis uero non credentibus, sed contradicentibus, trahitur, calumniatur eicitur (...). Cf. J. Alvarado Planas, El problema ..., pp. 117-118.
} 
No más fidedigna resulta la información transmitida por Ildefonso de Toledo, acerca de una prueba similar a la que fue sometido Montano, su predecesor en la Sede entre 521-531 ${ }^{36}$. Al igual que Bricio, Montano había sido acusado de haber mantenido relaciones sexuales. Aunque pocos datos se ofrecen acerca del contexto preciso de la aplicación de la ordalía, ésta tampoco tuvo lugar en el curso de un proceso, sino para librarse de una calumnia. Se supone que fue él quien aceptó el procedimiento. Éste exigió que el obispo llevara carbones sobre su ropa hasta que completara la celebración de la Misa, que, como cabe de esperar de un relato hagiográfico, no resultó dañada ${ }^{37}$.

El relato de Ildefonso, al igual que el de Gregorio, contiene algunos elementos que debilitan el valor de la información que aporta. También se trata de una narración de corte hagiográfico, tanto la omisión de la cronología del episodio como del nombre del acusador de Montano hace dudar de la historicidad de los hechos. Además, Ildefonso señala que la narración es de origen ora ${ }^{38}$. De todos modos, la semejanza de las situaciones (la acusación de trato con mujeres en el caso de ambos obispos) y el seguimiento de una práctica muy similar (la aplicación de carbones ardiendo sobre la vestidura de los dignatarios), permite advertir que se trataba esta ordalía de un uso excepcional, pero que se realizaba por convención, al menos, desde el siglo VI.

A finales de esa centuria se documenta la única mención de la ordalía del fuego en contextos procesales. Se encuentra en las actas del Concilio celebrado en Caesaraugusta en 592, cuyo canon II establece que las reliquias que hubieran estado en manos de los arrianos debían ser sometidas a dicha prueba en los siguientes términos:
El santo sínodo estableció que las reliquias halladas en cualesquiera lugares de la herejía arriana fueran presentadas por los sacerdotes que las encontraran en sus iglesias [y] después de haberlas entregado a los obispos, que se pruebe con fuego si habian sido ocultadas por quien quiera que fuese, $y$, una vez des- cubiertos, que sean separados de la reunión de las sagradas iglesias ${ }^{39}$.

La cláusula sinodal se ha interpretado de dos modos: como una ordalía que servía para distinguir las reliquias auténticas de las que no lo eran o como la destrucción ri-

\footnotetext{
${ }^{36}$ Sobre Montano de Toledo, cf. S. Iranzo Abellán, "Montano de Toledo", en M ${ }^{\mathrm{a}}$ A. Andrés Sanz, C. Codoñer, S. Iranzo Abellán, J. C. Martín, D. Paniagua (coords.), La Hispania visigótica y mozárabe. Dos épocas en su literatura, Salamanca, 2010, pp. 82-84

${ }^{37}$ Ild. Tolet., De uir. ill., Praef.: Nam Montanus sedis beatissimus praesul ut a se coniugalis conuersationis infamiam propulsaret, tamdiu aduptos ueste candentes narratur tenuisse carbones, donec Domino consecrans oblationem totius per semetipsum compleret Missae celebritatem; quod sacrificio expleto, prunarum ignis cum decore uestis adeo in concordiam uenit, ut nec uestis uim extingueret ignis, nec uis ignis statum laederet uestis (...); De uir. ill., II. Sobre estas noticias, cf. J. Alvarado Planas, El problema ..., p. 150.

${ }^{38}$ Ild. Tolet., De uir. ill., II: (...) antiquissima fidelique relatione narratur (...).

${ }^{39}$ Conc. Caes. II, c. II: Statuit sancta synodus ut reliquiae in quibuscumque locis de Arriana haeresem inuentae fuerint prolatae a sacerdotibus, in quorum ecclesias repperiuntur, pontificibus praesentate igne probentur quod si a quibuslicet occultate fuerint et detegentur a sacrosanctas ecclesias coetu segregentur.
} 
tual de las reliquias arrianas ${ }^{40}$. Pues no existe información alguna, documental o literaria, acerca de la aplicación de este canon, es difícil precisar sus términos. Para entenderla, conviene tener presente que el II Concilio reunido en Caesaraugusta trataba de resolver la incorporación del clero y de las instituciones eclesiásticas arrianas a la Iglesia Católica a resultas de la conversión del rey Recaredo y de los visigodos a la fe nicena. El canon primero decretaba que todos los clérigos arrianos serían consagrados de nuevo según los ritos de la Iglesia católica, siempre y cuando demostraran ser hombres de fe y de vida casta. La segunda disposición conciliar, a consecuencia de la anterior, determinaba que los sacerdotes que se hicieran cargo de una iglesia que administrada por los arrianos, si encontraban reliquias, debían entregarlas a su obispo, quien las sometería a la prueba del fuego. El canon advierte de cuál era su finalidad, y ésta era expresamente averiguar si habían sido ocultadas por alguien (quod si a quibuslicet occultatae fuerint). Se supone que si las reliquias eran auténticas y su culto grato a Dios, no serían dañadas por el fuego, pero que, si eran arrianas, quedarían deterioradas. En ese caso, era necesario encontrar al culpable -el responsable de la iglesia antes de su incorporación a la religión católica- y excomulgarlo, porque, se presume, no había actuado de buena fe al profesar el credo niceno.

Como se ha observado, con la excepción de las normas conciliares cesaraugustanas, las ordalías practicadas entre los romanos no se produjeron nunca en contextos judiciales. Se hacían por consenso entre las partes, como una solución previa al litigio judicial, costoso y, a menudo, inviable por la inconsistencia o inexistencia de pruebas testificales o documentales. Las más antiguas se venían celebrando en algunos templos consagrados a los cultos tradicionales, aunque de modo muy excepcional. El poder taumatúrgico atribuido a las reliquias de los santos difundió esta práctica entre los cristianos. La función de las ordalías fue cambiando con el paso del tiempo, hasta adquirir un cierto reconocimiento jurídico, al menos, dentro del ámbito eclesiástico. Aunque nunca se ha documentado su uso en instrucciones de causas, se puede deducir que desde finales del siglo IV hasta el siglo VI servían para verificar la culpabilidad de un sujeto cuando no existieran pruebas suficientes que dieran paso a la apertura de un proceso.

\section{Las ordalías entre los germanos}

Al igual que los romanos practicaban por costumbre ordalías entre los siglos IV y VII, también los germanos que habían venido a habitar en el territorio romano, antes

\footnotetext{
${ }^{40}$ La primera explicación ha sido defendida por Tejada e Iglesia y la segunda, por Villa-Amil, Orlandis y Alvarado. Cf. J. Tejada y Ramiro, Colección de cánones y de todos los concilios de la Iglesia de España y de América (en latín y castellano), Madrid, 1859, 130; J. Villa-Amil y Castro, "Del uso ...", p. 146; J. Orlandis Rovira, "Problemas canónicos en torno a la conversión de los visigodos al catolicismo", Anuario de Historia del Derecho Español, 32, 1962, pp. 301-321, esp. pp. 309-314; A. Iglesia Ferreirós, "El proceso del Conde Bera y el problema de las ordalías", Anuario de Historia del Derecho Español, 51, 1981, pp. 1-221, esp. pp. 79-80, n. 236; J. Alvarado Planas, El problema ..., pp. 151-152.
} 
y después del fin del Imperio de Occidente. El recurso a estos procedimientos probatorios no era universal. Cada pueblo tenía sus propias tradiciones ordálicas. Burgundios, ostrogodos, francos salios, ripuarios y lombardos, compartían la práctica del duelo, que parece desconocida por los visigodos ${ }^{41}$. La ya descrita prueba del caldero era conocida tanto por los francos ripuarios, francos salios y los visigodos ${ }^{42}$. Los francos ripuarios fueron quienes se mostraron más receptivos en admitir la aplicación de distintas formas ordálicas, pues daban por válida la lucha, el caldero y las suertes ${ }^{43}$. En algo coincidían todos los germanos, y en ello se distinguían de los romanos: en atribuir pleno valor probatorio a las ordalías, por lo que su celebración daba término a los litigios. El carácter concluyente de estas pruebas venía prescrito por la tradición. Este hecho no significa que las ordalías no fueran cuestionadas como medio de prueba. Teodorico permitía a los ostrogodos dirimir causas mediante el duelo, pero no lo hacía de buen grado, pues la calificaba de consuetudo peruersa, recomendando su desaparición, sin exigirla ${ }^{44}$. El rey franco Gontrán tampoco estaba muy convencido del resultado de la lucha entre el nieto de su cubiculario y el guarda de los Vosgos ${ }^{45}$. Pero si las ordalías ofrecían dudas, a partir de finales del siglo VI, y, sobre todo, a lo largo del siglo VII, las fuentes coinciden en identificarlas como Dei iudicium ${ }^{46}$. Pero conviene tener presente que una ordalía no es necesariamente un «juicio de Dios». En la Antigüedad tardía, la mayor parte de estas prácticas no son consideradas tales. Más bien, eran aceptadas como procedimientos que exigían valor, y en él se reconocía la razón jurídica.

\subsection{El duelo}

La lucha entre dos varones, partes o representantes de cada una de las partes en litigio, es quizá la ordalía mejor documentada entre los germanos, aunque sólo consta que fuera usada por burgundios, ostrogodos, francos ripuarios y lombardos. La Lex Burgundionum o Liber legum Gundobadi, recoge una disposición del año 502 que prescribía que cuando no fuera aceptado un juramento, el litigio se resolviera mediante el duelo. Dice así:

(...) Si la parte de a quien hubiera prestado juramento no quisiera aceptar la jura, sino que afirmara que podía ser convencido por su adversario de la fidelidad a la verdad mediante las armas, y la otra parte no se arredrara, que

\footnotetext{
${ }^{41}$ Cass., Var., III, 23-24; IX, 14 (Ostrogodos); Greg. Turon., Hist. Franc., VII, 14; X, 10; Fred. Chron., IV, 51; Lex Rib., XXXII, 4 LVIII, 2; Edict. Roth., c. 198 (Lombardos). Sobre el desarrollo histórico de cada uno de estos pueblos, cf. M. Lupoi, Alle radici ..., pp. 99-150.

${ }^{42}$ Pact. leg. Sal., LII (LIII), 1.5; Lex Rib., XXX, 1-2; LI. VI, 1, 3.

${ }^{43}$ Lex Rib., XXX, 1.

${ }^{44}$ Cass., Var., III, 23.

${ }^{45}$ Greg. Turon. Hist. Franc., X, 10.

${ }^{46}$ Greg. Turon., Hist. Franc., VII, 14; Fred. Chron., IV, 51; Edict. Roth., c. 198.
} 
no se niegue el permiso para luchar. Así, que uno de los mismos testigos, que hubieran sido convocados para prestar juramento, que se bata bajo el juicio de Dios. Porque es justo que no dude en luchar quien afirma sin vacilar que sabe la verdad de la causa, y ofrece juramento. Pero si el testigo de la parte que ofrece el juramento fuera vencido en ese combate, todos los testigos que se comprometieran a jurar (por él), que sean obligados a satisfacer una multa a título de trescientos sueldos, sin (la posibilidad de) presentar ninguna otra prueba $^{47}$.

La temprana mención del Dei iudicium, indirecta por otra parte, refleja el concepto que tenían los burgundios de la ordalía del duelo: era una manifestación del parecer divino sobre una querella. Conviene destacar que la lucha no era la primera opción en el juicio: sólo era aplicable si el acusado rechazaba realizar el juramento exculpatorio o si éste no era aceptado por la otra parte. Los términos de la ley eran, por el contrario, disuasorios: no se negaba la autorización, pero tampoco se recomendaba. La multa impuesta a los cojuradores de la parte perdedora, fijada en trescientos suelos, trataba también de impedir que se llegara a esta opción probatoria extrema: el «juicio de Dios» era un extremo a evitar, aunque legítimo. Si se llegaba al mismo, era por razones de prestigio social. Lo demuestra la práctica de que en la jura no sólo participen las partes, sino también quienes les son partidarios. El juramento colectivo, más allá de reforzar la veracidad de una declaración procesal, manifestaba la posición social de aquél a quien se exigía la jura, al exhibir la lealtad de sus partidarios ${ }^{48}$.

Las siguientes noticias aparecen en las Variae de Casiodoro, y no demuestran ningún tipo de conformidad con la práctica del duelo. En concreto, el rey Teodorico, en un texto redactado por Casiodoro, por entonces quaestor, comunicó a Coloseo, a la sazón, comes en Panonia Superior, que consintiera la ordalía del combate singular entre los godos, no sin instarle a acabar con estos usos, recordándole que las causas no se pueden resolver de ese modo entre romanos ${ }^{49}$.

\footnotetext{
${ }^{47}$ Lex Burgundionum, XLV: (...) Vt si pars eius, cui oblatum fuerit iusiurandum, noluerit sacramenta suscipere, sed aduersarium suum ueritatis fiducia armis dixerit posse conuinci, et pars diuersa non cesserit, pugnandi licentia non negetur. Ita ut unus ex iisdem testibus, qui ad danda conuenerant sacramenta, Deo iudicante confligat: quoniam iustum est, ut si quis ueritatem rei incunctanter scire se dixerit, et obtulerit sacramenta, pugnare non dubitet. Quodsi testis partis eius, quae obtulerit sacramenta, in eo certamine fuerit superatus, omnes testes qui se promiserant iuraturos, trecenos solidus multae nomine, absque ulla indiciarum prestatione, cogantur exsoluere. Cf. J. Gaudemet, "Les ordalies ...”, p. 104; J. Alvarado Planas, El problema ..., p. 144.

${ }^{48}$ M. Lupoi, Alle radici ..., pp. 433-446.

${ }^{49}$ Cass., Var., III, 23: Vt inter nationum consuetudinem peruersam Gothorum possis demonstrare iustitiam: (...) remoue consuetudines abominanter inolitas: is uerbis ibi potius, non armis causa tractetur: non sit coniunctum negotium perdere cum perire: abiurator alieni furtum, non animam reddat: (...). Cf. J. Alvarado Planas, El problema ..., p. 119. Sobre la cancillería de Teodorico y las funciones desarrolladas en su corte por Casiodoro, cf. J. J. O’Donnell, Cassiodorus, Berkeley, 1979; G. Vidén, The Roman Chancillery Tradition: Studies in the Language of Codex Theodosianus and Cassiodorus, Variae, Göteborg,
} 
El mismo Teodorico, muy poco después, acaso al cabo de un año, volvió a exhortar a los residentes en Panonia para que abandonaran la práctica del duelo con las palabras: ¿Por qué recurriréis al combate singular, los que no tenéis jueces venales? ${ }^{50}$. Frente a la idea de irracionalidad que suele atribuirse a la ordalía, ésta contaba con una ventaja que no ofrecía el proceso judicial, que era su aparente limpieza, frente a la venalidad de la justicia romana. Un pasaje de Amiano Marcelino demuestra que los romanos tenían una imagen muy negativa del sistema judicial ya a finales del siglo IV $^{51}$. Algunos romanos, al parecer, habían solicitado dirimir causas por medio de la lucha, para evitar otros males, aunque en ello debieron de influir los dignatarios ostrogodos. Se conoce un caso concreto: en otro texto debido a la mano de Casiodoro, posiblemente del año 526, y redactado cuando era magister officiorum, Atalarico, nieto y sucesor de Teodorico, prescribió a Gildila, comes de Siracusa, que los romanos sujetos a la autoridad goda debían ser juzgados conforme a las leyes y procedimientos romanos, aunque ellos no quisieran ${ }^{52}$. Atalarico adoptó esta decisión, basándose en una decisión de Teodorico que advertía que el duelo no formaba parte de los medios de resolución de litigios entre los romanos, y que sólo lo permitía entre los godos. Así lo señala: Defended vuestros derechos con las armas; dejad a los romanos que litiguen en paz conforme a las leyes ${ }^{53}$.

Las apreciaciones de Teodorico y Atalarico sobre las ordalías demuestran también en qué circunstancias adquirían valor probatorio. Este tipo de procedimientos eran útiles para administrar justicia en función del tipo de proceso que se siguiera. La tradición romana, en la que existían las ordalías, prefería resolver los litigios a partir de la interpretación de normas escritas. Los ostrogodos eran favorables a otras formas de dirimir causas, si se quiere, más expeditivas, como era la medición de fuerzas, principalmente, porque, a diferencia de los romanos, carecían de jurisprudencia casuística escrita suficientemente desarrollada ${ }^{54}$. A juzgar por lo que dice Casiodoro,

1984; V. A. Sirago, “I Goti nelle Variae di Cassiodoro”, S. Leanza (ed.), Flavio Magno Aurelio Cassiodoro. Atti della Settimana di Studi. Cosenza-Squillace, 19-24 settembre 1983, Soveria Mannelli, 1986, pp. 179205; Chr. Kakridi, Cassiodors Variae: Literatur und Politik im ostrogotischen Italien, München, 2005.

${ }^{50}$ Cass., Var., III, 24: (...) Cur ad monomachiam recurratis, qui uenalem iudicem non habetis? (...). Cf. J. Alvarado Planas, El problema ..., p. 119.

${ }^{51}$ Amm. Marc., XXX, 4. Cf. J. F. Matthews, “Ammianus on Roman Law and Lawyers", J. den Boeft, D. den Hengst, H. C. Teitler (dirs.), Cognitio gestorum: the Historiographical Art of Ammianus Marcellinus, Amsterdam, 1992, pp. 47-57.

${ }^{52}$ Cass., Var., IX, 14: Duorum negotia Romanorum etiam his inuitis ad tuum diceris uocare iudicium.

${ }^{53}$ Cass., Var., IX, 14: Vos armis iura defendite; Romanos sinite legum pace litigare. Cf. P. Amory, People and Identity in Ostrogothic Italy: 489-554, Cambridge, 1997, p. 72. G. Maier, Amtsträger und Herrscher in der Romania Gothica. Vergleichende Untersuchungen zu den Institutionen der ostgermanischen Völkerwanderungsreiche, Stuttgart, 2005, p. 93; M. Cellurale, "Romani y Gothi en Italia. La comunión de derecho en la república unida de Justiniano", Revista de Derecho Privado, 21, 2011, pp. 21-40.

${ }^{54}$ M. Lupoi, Alle radici ..., pp. 163-164; M. Bellomo, L'Europa del diritto comune, Roma, 1994 (Cito la traducción inglesa: The Common Legal Past of Europe: 1000-1800, Washington, 1997, pp. 34-42). La jurisprudencia romana, sin embargo, ejerció una importante influencia sobre la legislación de los 
ésta no dependía tanto de una vaga idea de justicia divina, cuanto de una medición de fuerzas. El razonamiento que guiaba estas pruebas debía de ser que la parte que llevaba la razón se empeñaría más en el combate, porque no hay referencias al «juicio de Dios». Los siracusanos que solicitaban al comes Gildila poder dirimir sus pleitos con las armas, no lo hacían por encomendarse a la justicia divina, sino por evitar un proceso judicial largo y costoso. La voluntad de Dios no aparece entre los motivos de su preferencia por la justicia de los germanos.

De todos modos, frente a la idea que atribuyen los textos recogidos por Casiodoro, la ordalía del duelo no era la primera opción para dirimir causas. La Lex Ripuaria (de los siglos VI ó VII), por ejemplo, prescribía el recurso a la lucha después de que una de las partes rechazara el fallo del séptimo juicio ante una asamblea (mallus $)^{55}$. En ese caso, en señal de rechazo, la parte renuente debía desenvainar la espada en presencia del juez y clavarla en un poste. Sólo en ese caso, comparecerían las partes ante el rey y lucharían para defender cada uno su causa. Al igual que en las referencias de Casiodoro, tampoco aquí hay indicios de que se trate de un «juicio de Dios», sino de una demostración de valor, pues los verbos empleados son studere y defendere ${ }^{56}$. Las expresiones son similares en otra cláusula de la Lex Ripuaria que proponía el duelo como medio para resolver las exigencias de un antiguo dueño para que su liberto volviera a su servicio ${ }^{57}$.

A partir de finales del siglo VI, sin embargo, el duelo comenzó a ser reconocido entre los francos como Dei iudicium. En principio, no consideraban que un duelo fuera necesariamente un «juicio de Dios». Pero en su tradición, el resultado de las batallas era una expresión de la justicia divina, como demuestra el relato de Gregorio de Tours del enfrentamiento entre Chilperico y Gontrán ${ }^{58}$. El mismo autor refiere que los legados enviados por Childeberto II en 584 ante el rey Gontrán para conseguir que entregara a Fredegunda, acusada del asesinato de Chilperico I, acabaron retándole

reyes germánicos, como lo demuestra la recopilación escrita de sus tradiciones normativas, con todo el esfuerzo de ordenación que representa, cf. A. J. B. Sirks, "Shifting Frontiers in the Law: Romans, Provincials and Barbarians", R. W. Mathisen y H. S. Sivan (eds.), Shifting Frontiers in Late Antiquity, London, 1996, pp. 136-145; P. S. Barnwell, "Jurists and Kings: Law and Custom in the Late Roman and Early Medieval West”, Past and Present, 168, 2000, pp. 6-29.

${ }^{55}$ Sobre la Lex Ripuaria (o Ribuaria) y el debate acerca de su cronología, cf. Th. J. Rivers, Laws of the Salian and Ripuarian Franks, New York, 1986; R. McKitterick, The Carolingians and the Written Word, Cambridge, 1989, p. 70, esp. n. 114. Sobre el mallus, entendido como asamblea con funciones judiciales que reunía a todos los miembros del pueblo, cf. M. Lupoi, Alle radici ..., p. 264.

${ }^{56}$ Lex Rip., XXXII, 4: Quod si ipsam strudem contradicere uoluerit et ad ianuam suam cum spata tracta accesserit et eam in protam siue in poste posuerit tunc iudex fideiussores ei exigat ut se ante regem praesentit et ibidem cum arma sua contra contrarium suum re studeat defensare.

${ }^{57}$ Lex Rip., LVIII, 2: Sed si quis in postmodum contrarius exteterit et dixerit quod eum quis inlicitum ordine ingenuum dimisisset et ipse cum gladio suo hoc studiat defensare.

${ }^{58}$ Greg. Turon., Hist. Franc., VI, 31: (...) Gunthramnus uero rex cum exercitu contra fratrem suum aduenit, totam spem in Dei iudicio conlocans. Qui die una iam uespere, misso exercitu, maximam partem a germani sui exercitu interficit. (...). Cf. J. Gaudemet, "Les ordalies ...”, p. 103. 
a luchar en campo abierto para obtener el iudicium Dei, expresando que sería Dios quien decidiría la causa. Pero el combate no se llevó a cabo ${ }^{59}$. También Gontrán, al encontrar los restos de un búfalo desollado en el bosque real de los Vosgos en el año 590 , dispuso que la responsabilidad por la muerte del animal se decidiera con una lucha entre el nieto de su cubiculario Cundón y el guarda de los bosques. El duelo se saldó con la muerte de ambos, de modo que tampoco se pudo hacer justicia, y, mucho menos, ésta podía ser una manifestación del Dei iudicium ${ }^{60}$. En este caso, quizá al propio Gregorio no le interesaba invocar la existencia del «juicio de Dios», toda vez que éste no se había mostrado satisfactoriamente. Incidencias a parte, en general, entre los francos se consolidó la idea de que el resultado del duelo era una expresión de la voluntad divina en favor de una de las dos partes contendientes. Así, el texto conocido como Crónica de Fredegario afirma que cuando la reina Gundeberga fue acusada ante su marido Caroaldo de intentar envenenarle en 627, el rey, de común acuerdo con los principales nobles del reino, decidió que tanto el acusador, Adalulfo, luchara contra un representante de Gundeberga, Pitón. Adalulfo mató a Pitón y fue exiliada durante tres años ${ }^{61}$. El texto califica expresamente la prueba de Dei iudicium.

Fuera del ámbito franco, la calificación del duelo como «juicio de Dios» está documentada entre los lombardos, en el Edictum Rhotari regis, del año 643, que obligaba a quien acusara a una doncella o mujer libre de ser fornicadora o prostituta sin

\footnotetext{
${ }^{59}$ Greg. Turon., Hist. Franc., VII, 14: At si aliquis est similis mihi, qui hoc crimen inpingat occulte, ueniat nunc palam et loquatur. Tunc o rex piisime, ponens hoc in Dei iudicium, ut ille discernat, cum nos in unius campi planitiae uiderit demicare. Cf. J. Gaudemet, "Les ordalies ...", p. 103.

${ }^{60}$ Greg. Turon. Hist. Franc., X, 10: Anno igitur XV. Childeberthi regis, qui est Gunthchramni VIIII. atque XX, dum ipse Gunthchramnus rex per Vosagum siluam uenationem exerceret, uestigia occisi bunali depraendit. Cumque custodem siluae artius distringeret, quis haec in regale silua gerere praesumpserit, Chundonem cubicularium regis prodidit. Quo haec loquente, iussit eum adprehendi et Cauillonum conpactum in uinculis duci. Cumque uterque in praesentia regis intenderent et Chundo diceret, numquam a se haec praesumpta quae obiciebantur, rex campum diiudicat. Tunc cubicularius ille, dato nepote pro se, qui hoc certamen adiret, in campum uterque steterunt; iactaque puer ille lancea super custodem siluae, pedem eius transfigit, moxque resupinus ruit. Puer uero, extracto cultro, qui de cingulo dependebat, dum collum ruentis incedere temptat, cultro sauciati uentre transfoditur. Ceciderunt ambo et mortui sunt. Sobre estos sucesos, cf. I. Wood, The Merovingian Kingdoms, 450-751, London, 1984, pp. 88102; R. Van Dam, "Merovingian Gaul and the Frankish Conquests", en P. Fouracre y R. MacKitterick (eds.), The New Cambridge Medieval History, Cambridge, 2005, 193-231.

${ }^{61}$ Chron. Fred., IV, 51: Tunc unus ex legatariis, nomine Ansoaldus, non quasi iniunctum habuisset, sed ex se ad Charoaldum dixit: Liberare poteras de blasphemia hanc causam; iube illum hominem qui huiuscemodi uerba tibi nuntiauit armari, et procedat alius de parte reginae Gundebergae; quique armatus ad singulare certamen, ut iudicio Dei, his duobus confligentibus, cognoscatur utrum huius culpae reputationis Gundeberga sit innoxia, an fortasse culpabilis. Cumque haec Charoaldo regi et omnibus primatibus palatii sui placuissent, iubet Adalulfum armatum conflictum adire certaminis, et de parte Gundebergae procurrentibus consobrinis Gundebergae et Ariberto, homo, nomine Pitto, contra Adalulfum armatus aggreditur. Cumque conflixissent certamine, Adalulfus a Pittone interficitur. Gundeberga statim de exsilio post annos tres regressa sublimatur in regnum. Cf. J. Gaudemet, "Les ordalies ...", p. 103.
} 
sobrado fundamento debía retractarse mediante juramento y satisfacer una multa de veinte sueldos. ${ }^{62}$ Pero, de persistir en la calumnia, estaba obligado a defender su actitud mediante la lucha, quedando la causa a merced del Dei iudicium ${ }^{63}$.

\subsection{El caldero}

Fuera de la población romana, tampoco la prueba del caldero aparece identificada como Dei iudicium. El procedimiento parece similar al descrito por Gregorio de Tours en su Miraculorum liber. El Pactus legis Salicae, de comienzos del siglo VI, refiere que esta ordalía se aplicaba cuando así lo decidía un mallus ${ }^{64}$. Por lo general, no se exigía la ordalía, salvo que el litigio careciera de pruebas testificales convincentes. Si se resolvía que la persona encausada se sometiera a la ordalía del caldero, de resultar en su contra la prueba, debía satisfacer una multa de quince sueldos a los que hubieran testificado en su favor. De obtener la razón en la prueba, sin embargo, estaba obligado a entregarles a sus valedores una compensación de tres sueldos ${ }^{65}$. También se aplicaba la ordalía si el acusado no aceptaba el laudo y reclamaba someterse a la prueba del caldero, debería satisfacer en concepto de compensación treinta sueldos en el caso de que el resultado le fuera adverso ${ }^{66}$. Para evitar abusos, una norma añadida al Pactus legis Salicae establecía que la ordalía debía celebrarse antes de que contasen catorce noches desde el rechazo del laudo, después de que el acusado declarara su versión bajo jura antes de doce noches ${ }^{67}$. Quien rechazara jurar o aceptar la ordalía, tenía como última opción antes de perder la causa rogar al rey que aceptara

\footnotetext{
${ }^{62}$ Sobre el Edictum Rhotari regis, cf. A. Cavanna, Nouvi problemi intorno alle fonti dell'Editto di Rotari, Roma, 1968.

${ }^{63}$ Edictum Rothari regis, c. 198: (...) Si quis puellam aut mulierem liberam (...) fornecariam aut histrigam clamauerit (...) praeueat sacramentum cum duodecim sacramentalis suos (...). Nam si perseuerauerit et dixerit, se posse probare, tunc per camphionem causa ipsa, id est, per pugnam, ad Dei iudicium decernatur. Sobre los términos de esta ley, cf. J. Gaudemet, "Les ordalies ...", p. 103; M. Lupoi, The Origins of the European Legal Order, Cambridge, 2006, p. 291.

${ }^{64}$ Sobre el Pactus legis Salicae, cf. K. F. Drew, The Laws of the Salian Franks, Philadelphia, 1991, pp. 52-56; V. Marotta, "Potere imperiale e diritti barbarici: il Pactus legis Salicae", en Atti del Convegno Società, diritto e istituzioni nei papiri ravennati (V-VIII secolo), 14-15 maggio 2010, Ravenna, Ravenna, 2010, pp. 1-9.

${ }^{65}$ Pactus legis Salicae, LII (LIII), 1: De manu ad ineum redemendam. Si quis ad hineum admallatus fuerit, forsitan conuenit ut ille qui admallatus est ad manum suam redemat et iuratores debeat dare; si talis causa est unde legitimi $D C$ dinarios qui faciunt $X V$ solidos si adprobatus fuerit reddere debuerat CXX dinarios hoc est solidos III manum suam redemat. Ed. K. A. Eckhardt, Pactus legis Salicae, Göttingen, 1955.

${ }^{66}$ Pactus legis Salicae, LII (LIII), 5: Si uero leodem alter alteri impotauerit et eum ad hinneum admallatum habuerit et cumuenerit ut ioratores donet et manum suam redemat MCC dinarios qui faciunt solidos XXX manum suam redemat.

${ }^{67}$ Pactus legis Salicae, LXXIII, 5: Si uero de leude eum rogatum habuit, debet qui eum roganit eum XII uideredo iurare et ipsas in XIV noctes eneo calefacere debet, et si ad ipsum placitum uenire dispexerit aut manum suam ad eneum mittere noluerit.
} 
un nuevo juramento en su presencia en el plazo máximo de cuarenta noches, debiendo comparecer con doce cojuradores ${ }^{68}$. Un decreto de Chilperico I, además, exige la aplicación de la prueba del caldero cuando se demostrara que habían mentido los testigos que habían prestado juramento en un juicio. En tal supuesto, el encausado debía someterse a la ordalía, y afrontar una multa de quince sueldos, con independencia de que su mano resultara dañada por el agua hirviente ${ }^{69}$. Pero la ordalía del caldero no era concluyente. Su valor dependía del que le atribuyeran el juramento de quienes estuvieran dispuestos a testificar por la parte sometida a la prueba. En ocasiones, la ordalía podía ser rechazada o incluso ignorada. La última voz en una causa germánica, no la tenía la ordalía (que no aparece designada como juicio de Dios), sino el rey, máxima instancia judicial. El monarca era quien decidía el final del proceso.

A la ordalía del caldero también hace referencia una ley visigoda, conservada en algunas versiones del Liber iudicum, atribuida convencionalmente a Egica, aunque sin completa certeza. En cualquier caso, parece que es de finales del siglo VII, aunque el texto actualmente conservado está muy alterado ${ }^{70}$. La examinatio caldaria o prueba del caldero era excepcional en Hispania, y se aplicaba en causas cuya responsabilidad civil no superaba los trescientos sueldos ${ }^{71}$. La ley hispana establece que los acusadores, de demostrarse la inocencia del encausado, no serían castigados por el delito de calumnia ${ }^{72}$.

La prueba del caldero se aplicaba para delitos de naturaleza económica. No solían ser causas graves, y éstas, siempre que fueran por razones económicas. De nuevo, la ausencia de la mención al Dei iudicium es patente, por lo que cabe proponer otra explicación de la ordalía: la de que se trate de un procedimiento para concluir causas de

\footnotetext{
${ }^{68}$ Pactus legis Salicae, LXXIII, 6: Quicumque anstruscio ille de causa superius conpraehensa per sacramenta absoluere non potuerit aut manum suam in eneum pro leude mittere dispexerit aut in placito uenire distulerit, tunc ille, qui eum rogatum habet, solem illi collicet ad ipso die in mallobrego in XL noctes. (...). Et postea illum in praesentia regis ad noctes XIV rogare debet, et ibi XII ponat, qui per singulas uices iurati dicant (...).

${ }^{69}$ Pactus legis Salicae, CXXXII: Si qui falsi testes fuerint adprobati, quinos denos solidos multa sustineat, si uero eis inculpauerit, quod falsum testimonium dedissent, manum suam in ineum mittat, et si sana tulerit, sicut superius diximus, simili multa sustinenant. Si certe manum suam conburet, $X V$ solidorum damnum sustineat.

${ }^{70}$ Iglesia niega su historicidad (Cf. A. Iglesia Ferreirós, "El proceso ..., pp. 82-84). Los estudios de García López y Alvarado Planas avalan su autenticidad. Cf. Y. García López, Estudios de la Lex Wisigothorum (Memorias del Seminario de Historia Antigua, V), Alcalá de Henares, 1996, pp. 513-554; J. Alvarado Planas, El problema ..., pp. 179-190.

${ }^{71}$ A. Iglesia Ferreirós, "El proceso ...", pp. 82-83.

${ }^{72}$ LI. VI, 1, 3: Quomodo iudex per examine caldarie causas perquirat. Multos cognouimus querellasse ab ingenuis multa mala pati, credientes in trecenorum solidorum questio agitari. Quod nos modo per salubrem ordinationem censemus ut quamis parue rei sit facti criminis, eos per examinationem caldarie a iudice districtos peruenire ordinamus; et dum suas dederint processiones, superiori lege subiacebunt. Quod si per examinatione kaldarie sumam innocentia patuerit, petitor nullam calumniam patiatur. Hoc quoque erit et de suspectis habentibus personas qui ad testimonium uenerint dicendum, hic ordo seruabitur.
} 
otro modo irresolubles. Cuestión distinta es que se le atribuyera el valor de «juicio de Dios», pero al margen del ordenamiento normativo. No se le atribuía a la prueba del caldero un carácter infalible, sino concluyente. Si el Pactus legis Salicae establecía que la pena pecuniaria debía ser inferior al dinero reclamado es porque, en ese momento y contexto legislativo, la ordalía no tenía suficiente valor probatorio. Trata de alcanzar un acuerdo entre las partes. En cualquier caso, como tampoco probaba la inconsistencia de una acusación, puesto que la ley visigoda no considera oportuno castigar a los acusadores por calumnia. La ordalía del caldero, por tanto, no probaba plenamente la veracidad de las acusaciones, pero tampoco demostraba la inocencia de un acusado, ya que protegía a los demandantes de cualquier intento de imputación por calumnia.

Tampoco gozaba de la condición de Dei iudicium entre los ripuarios, a juzgar por lo señalado en la Lex Ripuaria ${ }^{73}$. En su caso, se aplicaba para regular las obligaciones de los dueños con relación a sus siervos. Si un siervo procesado por un delito, su dueño estaba obligado a declarar si conocía o no la culpabilidad de su esclavo con relación a un robo. Una vez hecho esto, el siervo era sometido a la prueba del caldero o a las suertes. Si el resultado de la ordalía le era desfavorable, al descubrir la mano dañada, el dueño sería declarado igualmente culpable ${ }^{74}$. Por otra parte, si un siervo encausado se daba a la fuga, su dueño debía responder por él, jurando que se había huido sin su conocimiento, y que se comprometía a hacerle comparecer en el plazo máximo de cuarenta días con sus noches, o, si no, a someterse él en su lugar a la prueba del caldero $^{75}$. Del mismo modo, si un acusado no podía presentar testigos que juraran para confirmar su juramento, debía someterse a la ordalía del caldero o a la de las suertes ${ }^{76}$.

Esta última forma de ordalía, la de las sortes, muy escasamente documentada y peor conocida, parece tener un carácter subsidiario en relación con el duelo. Si tuvo menor relevancia que el lance, quizá fue porque no suponía ninguna exhibición de valor en una sociedad que lo requería ${ }^{77}$. De acuerdo la exigua información que proporciona la

\footnotetext{
${ }^{73}$ Sobre la Lex Ripuaria, cf. Th. J. Rivers, Laws of the Salian and Ripuarian Franks, New York, 1986. ${ }^{74}$ Lex Rip., XXX, 1: Quod si quis in iudicio pro seruo interpellatus fuerit quod si seruos tales non fuerit unde dominus eius de fiducia securus esse posset in iudicio respondeat ad interrogationis stabat liceat ei sine tanganu loquere et dicat: Ego ignoro utrum seruos meos culpabilis an innocens ex hoc extederet; propterea eum secundum legem Ribuariam super noctis XIV ad igneum seu ad sortem repraesento. Et sic eius praesentiam cum fistuca fidem faciat. Quod si seruus in igneum manum miserit et lesam tullerit dominus eius sicut lex contenit de furtu serui culpabilis iudicetur.

${ }^{75}$ Lex Rip., XXX, 2: Quod si seruus quando dominus interpellatur, infra ducato fuga lapsus fuerit super $X I V$ noctis aut ipsum repraesentit aut pro eum faciat rationem. (...) Quod si postquam eum ad igneum placuerit fuga lapsus fuerit ad placitum ueniens cum tribus testibus in haraho coniurit quod seruus illi quem ad igneum repraesentare debuerat extra eius uoluntate fuga lapsus sit et sic denuo placitus ei concidatur ut super XIV noctes seu super XL noctis eum repraesentare studeat aut ipse in rem respondeat.

${ }^{76}$ Lex Rip., XXXI, 5: Quod si in prouincia Ribuaria iuratores inuenire non potuerit, ad igneo seu ad sortem excusare studeat. Cf. J. Alvarado Planas, El problema ..., p. 136.

${ }^{77}$ Véase al respecto, por ejemplo, el elenco de valores que caracterizaban al buen guerrero en la Hispania visigoda, cf. E. Moreno Resano, "La representación épica del guerrero y el combate en la inscripción de Opilano (año 642)”, Habis, 42, 2011, pp. 297-314.
} 
Lex Ripuaria, no se puede afirmar a qué tipo de suertes hace referencia. Es difícil pensar que aluda a las sortes evangélicas, que consistían en abrir al azar un ejemplar del Nuevo Testamento, o a las sortes Sanctorum, que, aunque debían existir desde el siglo V, no adquirieron una forma definitiva hasta bien entrada la Edad Media ${ }^{78}$. Más bien debían de ser procedimientos adivinatorios, comparables a los auspicios de los romanos, de los que Tácito procura algunos ejemplos, aunque del siglo I d. C..$^{79}$

\section{Conclusiones}

Las ordalías fueron procedimientos empleados en la Antigüedad tardía para resolver querellas tanto entre los ciudadanos romanos como entre los pobladores germanos que acabarían constituyendo diferentes reinos en el antiguo solar del Imperio de Occidente. Pero su valor y funcionalidad eran diferentes en cada caso. Los romanos las usaban, aunque no les otorgaban valor jurídico alguno. Cada pueblo germano tenía sus particulares usos ordálicos, $\mathrm{y}$, a falta de un cuerpo jurisprudencial exhaustivo, reconocían valor decisorio a los resultados de la aplicación de estos procedimientos. Este hecho no impidió, como se ha podido verificar en la Italia sujeta a la autoridad ostrogoda, que la desconfianza de los romanos en su sistema jurídico les hiciera perseguir la resolución de sus litigios siguiendo los usos de los germanos. Más allá de si el sistema normativo y judicial romano era más racional y «civilizado» que los que tenían los germanos, lo que permiten deducir las fuentes es que incluso los súbditos romanos de los reinos germánicos requerían formas de justicia resolutivas, antes que enfrentarse a procesos largos y costosos, de resultado incierto.

En consideración a estas observaciones, las ordalías se pueden definir como procedimientos empleados para resolver conflictos de carácter judicial cuando las pruebas testificales o documentales eran inconsistentes. Si tales formas eran el resultado de la intervención divina en los pleitos de los hombres, dependía de las tradiciones de cada pueblo y de las circunstancias que afectaban a las causas. La Iglesia, fiel a la tradición canónica, se mostraba en esta época desafecta a estos medios, aunque solía aceptarlos para dar término a querellas doctrinales. En realidad, fuera del ámbito estrictamente religioso, la ordalía era una exhibición de valor por parte de quien se sometía a ella. Su lógica parece estar en que la persona a la que corresponde la razón jurídica es la que más empeño pondría en exponerse a una prueba dolorosa, como era el caldero, o peligrosa, como el duelo.

Por otra parte, la identificación de las pruebas ordálicas como Dei iudicium no era general y tampoco es inherente a ellas: sólo los francos salios y los lombardos les reconocían este carácter, en virtud de sus tradiciones. Cierto es, no obstante, que esta

\footnotetext{
${ }^{78}$ Véase al respecto, cf. E. Moreno Cartelle, Los «libros de suertes» medievales: las Sortes Sanctorum y los «Prenostica Socratis basilei», Madrid, 2004.

${ }^{79}$ Tac., Germ., VIII, 2; X, 1-2. Cf. J. Alvarado Planas, El problema ..., pp. 139-140.
} 
asimilación se generalizó a partir del siglo VII. En algunas legislaciones germánicas se contemplaba su uso, pero sin reconocerle una validez absoluta. Las ordalías suponían una exposición, al menos, potencial o real al riesgo físico, pero este hecho no era sino el reflejo de una vida social acostumbrada a la violencia. No es que ésta no existiera antes, pero la crisis de los valores cívicos que siguió a la desaparición del Imperio en Occidente exigió la creación de nuevos códigos normativos que regularan el empleo de la fuerza. Estas normas eran de origen consuetudinario, pero luego fueron recogidas en las distintas leyes germánicas. Por ello, eran formas de reparar los conflictos que surgieran dentro de las distintas comunidades, cuya aceptación se fue consolidando a lo largo de los últimos siglos de la Antigüedad. 